\title{
Corporate strategies oriented towards sustainable governance: advantages, managerial practices and main challenges
}

\author{
Ivo Hristov ${ }^{1}$ (D) Antonio Chirico ${ }^{1} \cdot$ Francesco Ranalli $^{1}$
}

Accepted: 2 May 2021 / Published online: 24 May 2021

(c) The Author(s) 2021

\begin{abstract}
In the face of advancing globalization, societies have undergone a significant transformation over the last decades. The resulting environmental, social, economic and institutional challenges have made the issue of sustainability more relevant than ever, touching every aspect of our lives. To respond to these challenges, institutions and companies must jointly pursue the common goal of sustainable development. However, to integrate sustainability in strategic decision-making, academics and managers require a clear view of the advantages, key value drivers and potential solutions. Accordingly, we focus on two questions: What are the advantages of integrating sustainability initiatives in strategic decision-making? How can sustainability be integrated in the corporate strategy with a view to sustainable development? Based on semi-structured interviews with 85 managers specialized in sustainable governance, we provide a clear picture of the role of sustainability in the value creation process. Our proposed conceptual model suggests a positive correlation between implementing sustainability initiatives and corporate performance. Moreover, our findings show that firms that effectively implement sustainability improve the conditions of their surrounding communities. Indeed, a sustainable corporate strategy can lead not only to superior performance, but also to improving the wellbeing of all stakeholders.
\end{abstract}

Keywords Performance $\cdot$ Corporate strategy $\cdot$ Sustainable governance $\cdot$ CSR . Survey

Ivo Hristov

hristov@economia.uniroma2.it

1 Department of Management and Law, University of Rome Tor Vergata, Via Columbia 2,

00133 Rome, Italy 


\section{Introduction}

The effects of climate change and the degradation of the environment have become critical issues, and experts state that in just a few years, these effects will be irreversible. As such, the need for individuals and companies to roll up their sleeves to change the current direction of events is pivotal and urgent. Only in the last two decades have companies started to become aware of the need to adopt sustainable practices (Cantele \& Zardini, 2018), recognizing the environmental impact of their activities, and realizing the importance of jointly addressing sustainability issues in the social, environmental and economic sphere (Adams \& Frost, 2008). While governments and businesses may now acknowledge the sustainability issue, the increasingly alarming problems require concrete and urgent actions to find effective and efficient solutions. Social and environmental responsibility is neither detached from nor in opposition to a corporate strategy based on economic objectives (Bhattacharyya, 2019), and should be a fundamental component of integrating sustainability with a view to long-term benefits aimed at the creation and distribution of value (Chalmeta \& Palomero, 2011). Integration is here intended as an organizational system that brings together the sub-system of components to ensure a coordinated whole (Lawrence \& Lorsch, 1967). Sustainability is one such component of the corporate strategy (Suganthi, 2019) and a vehicle to sustainable development.

Despite the significant and growing literature recognizing the potential of sustainability at the strategic level (Figge et al., 2002; Morioka \& de Carvalho, 2016; Sahut et al., 2019), its integration with corporate strategy and managerial practice remains suboptimal (Braune et al., 2019) for two main reasons: First, the absence of a clear picture, data and empirical evidence of the advantages of integrating sustainability in the corporate strategy. From a management perspective, to the best of our knowledge, few studies focus on the advantages and performance drivers of practical solutions to integrating sustainability in the corporate strategy (Parisi, 2012). While some studies suggest that sustainability is positively linked to performance (e.g., Liao, 2018; Magon et al., 2018; Wang et al., 2016; Xie, Nozawa, et al., 2019), the findings are not supported with evidence from a managerial perspective, instead justifying the theoretical approach with international standards and reports. In addition, and inconsistently, other studies assert a negative relationship between sustainability and performance (e.g., Cantele \& Zardini, 2018; Lewandowski, 2017; Miroshnychenko et al., 2017). The second reason, linked to the first, is the absence of practical solutions and strategic tools that support managers in implementing sustainable strategies. Limited research has focused on practical approaches to adopting a sustainable strategy (Bisbe \& Malagueño, 2012; de Villiers et al., 2016; Parisi, 2012). Accordingly, without alternatives, managers are forced to make recourse to traditional accounting systems and financial measures (Michelon \& Parbonetti, 2010).

To summarize, a review of this literature shows a lack of clarity and some confusion on which performance drivers are linked to the integration process, thus requiring more attention in managerial practice. We can only hypothesize that 
sustainability has a positive impact on firm performance given the mixed results and the absence of managers' perceptions or insights on this relevant topic (Geng et al., 2017; Michelon \& Parbonetti, 2010; Zhu et al., 2012).

Therefore, to address this gap in the literature and advance the field, the present study focuses on managers' perceptions and managerial practices related to sustainability. Given these premises and the need to clearly identify the impact on performance of integrating sustainability in the corporate strategy, this study has a twofold purpose:

(1) Provide a clear picture of the advantages for managers and organizations that implement corporate strategies oriented towards sustainability.

(2) Identify the managerial practices, measures and key challenges related to integrating sustainability in the corporate strategy.

With regard to the first purpose, we analysed the literature and conducted semi-structured interviews with a sample of 85 managers who clearly describe their corporate sustainability policies and the perceived advantages. We identify four main performance areas and key dimensions that managers perceive positively: financial performance, stakeholder perceptions, image and reputation, and cultural change. These dimensions play a crucial role in strategic decisions on whether to implement a sustainable strategy or not. For each dimension, we provide a comprehensive analysis of the key value drivers linked to performance. Through interpreting the sustainability drivers considered relevant in the value creation process, we identify the main performance outcomes. Our findings thus offer managers a clear view of the competitive advantages of increasing their sustainability knowledge and management experience (Cinquini \& Mitchell, 2005) in everyday matters, supporting decision-making on the implementation of a sustainable strategy.

With regard to the second purpose, specific sections of the questionnaire were aimed at analysing and discussing the practices, measures, main challenges and criticalities to provide practical solutions to the integration process. Accordingly, we built a strategic scorecard based on a set of key performance indicators (KPIs) and goals designed to implement, monitor and manage sustainable strategies.

Our findings suggest that integrating sustainability at the strategic level requires incorporating sustainability in the organizational culture. The managers affirmed that sustainable development is first of all a cultural factor that requires understanding and acceptance and is, at the same time, a critical and a difficult challenge.

We develop a theoretical framework that posits sustainability as a key element of responsible and successful organizations that proactively place themselves in the environment. The framework is based on three main pillars. First, sustainability needs to be incorporated at an early stage, namely when planning and formulating the corporate strategy. Second, the scorecard analyses each of the four dimensions (environment, culture, economic and social) in terms of sustainability goals, measures, processes and targets. Indeed, given the premises and the 
managers' assessments of the critical issues and challenges, we added the cultural dimension to the traditional triple bottom line (TBL). The third relates to clearly defining and discussing the potential impact on performance when sustainability is integrated at the strategic level.

The remainder of the paper is structured as follows. Section 2 provides the theoretical background on the main issues we address. Section 3 develops the research methodology, followed by the findings (Sect. 4), sustainable management practices and main challenges (Sect. 5). Section 6 discusses the results and future research directions. Section 7 concludes the study.

\section{Theoretical background}

\subsection{Management control and sustainable development}

Management control has a significant role in the decision-making process, integrating several phases aimed at guaranteeing strategic alignment between the corporate strategy, actions and operations (Burney et al., 2009; Busco et al., 2007; LangfieldSmith, 2007). Developing the performance of individuals and teams allows a strategic plan to be defined according to a cause-effect relationship (Chenhall, 2005; Cinquini \& Tenucci, 2010). One of the main challenges for companies and managers is generating sustainable value in a long-term perspective, integrating sustainability in governance and corporate strategy-making (Barnett, 2007; Barnett \& Salomon, 2006). This is indispensable to guarantee economic development compatible with social equity and respect for ecosystems based on a balanced and interconnected relationship between the TBL (economy, society and environment) and corporate strategy (Perego \& Hartmann, 2009). In particular, the implementation of a structured management control system oriented to sustainability is fundamental for firms to overcome the new challenges posed by the environmental context (Hull \& Rothenberg, 2008).

As mentioned, one research stream suggests potential positive effects of integrating sustainability in the corporate strategy mainly in terms of financial advantages (e.g., Charlo et al., 2013; Hsu \& Chen, 2015; McWilliams \& Siegel, 2000, 2001; Wang et al., 2016; Xie, Huo, et al., 2019; Xie, Nozawa, et al., 2019), and image and reputation (Cai \& Li, 2018; Liao, 2018). Yet, little is known about the main sustainability dimensions that managers consider in practice, and how they might impact overall corporate performance (Adams, 2002; Burke \& Logsdon, 1996). As a result, sustainability issues have often remained disconnected from the corporate strategy, leaving the contribution to performance uncertain.

This has prompted our first research question, and is likely the most complex and critical, particularly given the impossibility of providing a unique and standard solution for organizations of different types, sizes, sectors and many others factors. Accordingly, supported by the managerial experiences, we attempt to provide the clearest picture possible of the main sustainability dimensions as positive drivers of performance in the decision-making process. 


\subsection{Sustainability and corporate strategy}

We analyse two different research streams on sustainability and corporate strategy. The issue of sustainability planning is increasingly important in corporate strategy (Braune et al., 2019). The integration of sustainability is recommended by the main international standards, guidelines and strategic documents, such as the European Commission Corporate Social Responsibility (CSR) recommendations underlining the importance of a long-term strategic approach to sustainability. Sustainability integration is part of the ISO 26,000 guidelines referring to the inclusion of social responsibility as a key element of the organization's strategy, the Global Reporting Initiative (GRI), and the integrated reporting framework of the International Integrated Reporting Council (IIRC), referring to the strategic focus of sustainability and future orientation (Adams \& Frost, 2008; de Villiers et al., 2016).

The most frequently studied dimensions of sustainability are the role, use and measures from a social science perspective (Azevedo et al., 2012; Trianni et al., 2019), and corporate governance in relation to business management and accounting (Cinquini \& Tenucci, 2010). Although both dimensions have been amply studied and discussed, few studies focus on an integrated approach (Farias et al., 2019; Figge et al., 2002; Morioka \& de Carvalho, 2016).

Indeed, the relationship between these dimensions has been analysed mainly in two ways. The first, strictly linked to social responsibility, is the CSR discipline (Barnett \& Salomon, 2006), providing a bridge between sustainability issues and corporate strategy, customers, employees and communities to create a culture oriented toward the social and environmental consequences of business activities. The second aspect, from a strategic point of view, is the KPI system. Several recent studies have focused on the relevant role of performance indicators in implementing a sustainable strategy (Acquaye et al., 2014; Bai \& Sarkis, 2014; Bini et al., 2015; Hristov \& Chirico, 2019; Le Tellier et al., 2019), and integrating sustainability in the corporate strategy (Bansal \& Bogner, 2002; Figge et al., 2002; Morrow \& Rondinelli, 2002). Indeed, CSR and the KPI system are used to explain the relation between sustainability and corporate strategy from different perspectives, albeit distant and lacking integration (Sahut et al. 2019). In fact, sustainability reporting is considered a secondary dimension aimed mainly at improving corporate image and reputation, but often not really linked to corporate strategy.

Therefore, we propose a theoretical model aiming to synthetize the relation between sustainability and corporate strategy (Fig. 1).

Dimension (A) in the figure represents sustainability disclosure based on the TBL approach (dashed grey oval). The environmental, social and economic dimensions are strictly correlated. Considering these dimensions in corporate governance enhances the organizational process and moves the firm's perspective from value creation to a sustainable value orientation, as well as correlating stakeholder needs with the firm's goals. This dimension is mainly measured and implemented with the use of sustainability KPIs (link 1), an integrated approach to internally add value to the role of sustainability. The second approach, externally oriented, is CSR corresponding to stakeholder engagement (link 2). Moreover, both CSR and the KPI system have a significant impact on the second dimension (B), the corporate strategy 


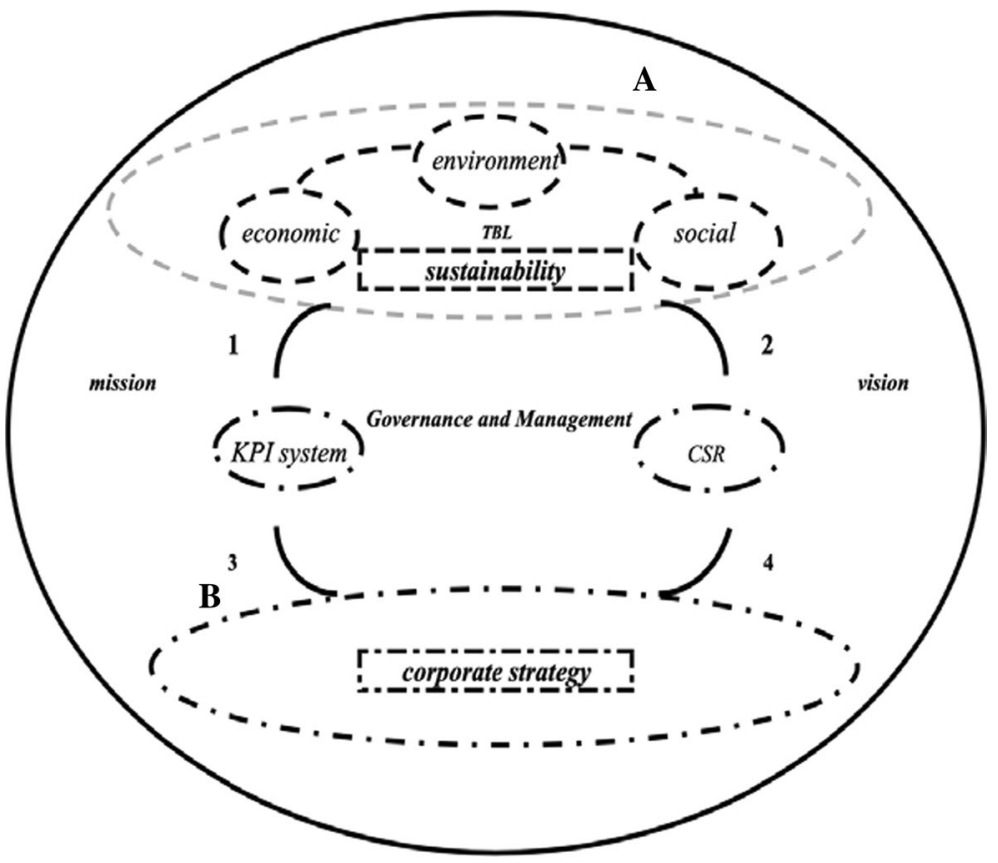

Fig. 1 Sustainability strategy

(dashed black oval). From a strategic point of view, the KPI system is an expression of the firm's performance management system (PMS) through selecting, implementing, monitoring and refining the corporate strategy (link 3). This systematic process allows implementing the corporate strategy and supporting managers in each step of the decision-making process. Finally, an additional and important connection (link 4) between corporate strategy and CSR is planning disclosure as part of the corporate strategy and increasing shareholder value.

Therefore, while CSR and the KPI system link sustainability and corporate strategy, they remain detached. Although both dimensions impact the firm's governance and management, they tend to be analysed separately and discussed within their boundaries. Instead, our conceptual model integrates sustainability and corporate strategy by widening these boundaries.

\section{Research method}

\subsection{Sample design and data collection}

We collected data from a sample of 85 managers specialized in sustainable corporate strategy through (1) a survey questionnaire for the sampling and preliminary data, and (2) an interview questionnaire for data selection and analysis, leading to a structured analysis of the advantages of adopting a sustainable corporate strategy 
Fig. 2 Sample selection

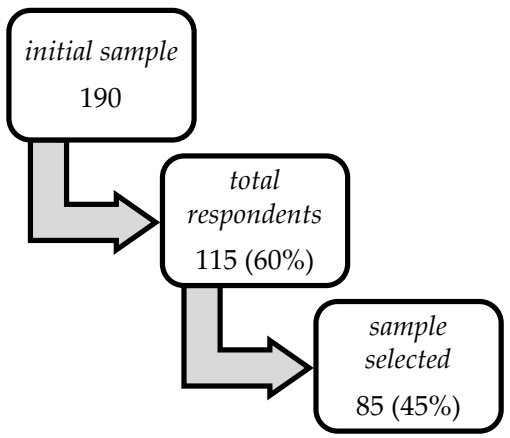

in business management and governance. We selected the respondents using the AIDA $^{1}$ database and personal contacts, emailing a web-based questionnaire to 190 managers for some basic information and their experience with sustainability issues. More specifically, the selection criteria included companies with over 100 employees, as they are expected to have more sophisticated PMS to manage sustainable integration (Lisi, 2015). In particular, in the first section of the questionnaire, we focused on the general demographics, and in the second section, on work experience with sustainability issues. We received a total 115 responses (60\% response rate). To ensure selection quality, we identified the managers to include in our final sample on the basis of their experience (more than 5 years managing sustainability issues) and position (middle and top managers). Of the 92 managers we identified and contacted by email to verify their availability for face-to-face interviews, 85 confirmed their participation (Fig. 2).

In terms of industries, our respondents are from the manufacturing (34\%), tourism $(27 \%)$, healthcare (19\%), food and beverage (13\%) sectors, and the remaining $7 \%$ in information technology, finance, and education services. Table 1 presents the descriptive statistics. A large proportion of the sample is male, aged 45+years, and middle managers with more than 5 years experience.

\subsection{Interviews and variables analysed}

The interviews with the 85 managers (54 face-to-face and 31 by phone) lasted $45 \mathrm{~min}$ on average (from 33 to $57 \mathrm{~min}$ ), and all the data were analysed by categorizing the responses into the main conceptual dimensions. In particular, our research questions guided the development of the questionnaire, resulting in three different sections covering 20 questions (Appendix). The first section explores the advantages of a sustainable strategy linked to management and governance. The second investigates the practices and measures related to integrating sustainability in the corporate

\footnotetext{
1 An online database containing financial, personal and commercial information on over 500,000 jointstock and financial companies in Italy.
} 
Table 1 Sample description

\begin{tabular}{llrr}
\hline Gender & Male & 63 & 74 \\
& Female & 22 & 26 \\
& Total & $\mathbf{8 5}$ & $\mathbf{1 0 0}$ \\
Year & $>50$ & 19 & 22 \\
& $45-50$ & 42 & 49 \\
& $<45$ & 24 & 29 \\
Job position & Total & $\mathbf{8 5}$ & $\mathbf{1 0 0}$ \\
& Top manager & 28 & 33 \\
& Middle manager & 57 & 67 \\
Job experience in sustain- & Total & $\mathbf{8 5}$ & $\mathbf{1 0 0}$ \\
able strategy (years) & 5-10 & 31 & 36 \\
& Total & 54 & 64 \\
& & $\mathbf{8 5}$ & $\mathbf{8 5}$ \\
\hline
\end{tabular}

Bold indicates total sample interviewed

strategy. The last section explores the main challenges and critical issues related to the integration process.

\subsection{Validity and rigour of the method}

All the raw data were transcribed after the interviews, then interpreted and categorized into the defined conceptual areas. We asked the respondents to check the information transcribed from the interviews for potential inaccuracies (Bortolotti et al., 2015). To verify and improve the validity of the results, we contacted the managers several times (three rounds after the initial interviews) to discuss the summary findings and make any changes requested. To improve internal validity and reduce researcher bias, we triangulated the data collected from the interviews with secondary data from the literature reviewed (Eisenhardt \& Graebner, 2007).

\section{Research findings}

We have divided our research findings into two parts. The first explores the advantages related to integrating sustainability in the corporate strategy (RQ1). The second, presented in Sect. 5, identifies the practices and measures (strategic dimensions and sustainable KPIs), main challenges and critical issues in the integration process (RQ2). Finally, we offer a conceptual framework (Sect. 6) that provides a way to consider and integrate key sustainability issues in the corporate strategy.

In line with our first purpose, after the interviews, we read and analysed the managers' responses, clustering the information related to specific outcomes. Once the clusters were generated, we re-contacted the managers (first round) to discuss the interpretation of the qualitative data and make the required changes. Thereafter, we identified four main performance outcomes (financial performance, image and 
reputation, stakeholder perception, and cultural change) representing the drivers of value creation in integrating sustainability at the strategic level, as we next explain.

\subsection{Financial performance}

The first performance outcome that emerged from the analysis and interpretation of the managers' responses is the financial dimension. All of the 85 managers interviewed offered an in-depth discussion on how the integration between sustainability and strategy brings advantages in terms of financial performance. For instance, from the question "What are the main advantages of integrating sustainability in the corporate strategy?" (Question 2, Appendix), we conclude that implementing sustainability at the strategic level has positive effects on financial performance, mainly in terms of cost reduction and revenue growth. The managers discussed several key issues supporting this conclusion, particularly with regard to material substitution, fewer resources needed to store materials, green packaging, lowering energy consumption in the production processes, and waste disposal. In particular, the data lead us to conclude that sustainability is strongly linked to financial performance, as managers emphasized the relevant role of using, reusing and recycling the lowcost inputs, and the benefits of renewable sources. Thus, these sustainable activities are all substantial opportunities to increase efficiency and productivity and, consequently, cost reduction and revenue growth. In addition, the managers highlighted that eco-innovation, initially seen as increasing costs, is now considered an opportunity to improve overall performance. In fact, Przychodzen and Przychodzen (2015) focus on the financial advantages of eco-innovators, suggesting that engaging in eco-innovation investments translates into positive effects on return on assets (ROA) and return on equity (ROE), and that eco-innovative firms are less exposed to financial risks and obtain greater free cash flow than firms that do not engage in such innovation.

In addition, the managers affirmed that, after an initial investment to integrate sustainability initiatives in the organization, the positive financial impact on average registers after $2 / 3$ years. This lag is mainly due to the time required to ensure integration between the business units (sustainability-oriented culture) and implementing the environmental and social initiatives. Thus, our respondents confirm the hypothesis of a positive relationship between a sustainable corporate strategy and financial performance.

\subsection{Corporate image and reputation}

The second performance outcome is the advantage in terms of image and reputation, strongly linked to the integration process. We raised the question as to whether or not being efficient leads to benefits in terms of increased reputation. Sixty-five managers highlighted that sustainability integration at the strategic level is positively perceived outside the firm, particularly by actual and potential clients. The managers suggested that a positive image and reputation allows the generation of 
further opportunities in terms of new collaborations, new market segments, stronger customer loyalty, and social initiatives in collaboration with universities and public institutions, helping firms achieve a competitive advantage and increase brand value. Moreover, an alternative point of view emerged from the interviews. The managers suggested they consider the potential negative impact on image and reputation when sustainability is not integrated in the strategy, since the negative effects generated by the organizations' activities linked to the consumption of energy and water resources, gas emissions, waste management and so forth affect customer perceptions. Hence, the image and reputation engendered by integrating sustainability at a strategic level is a relevant issue that affects customer decisions (Cai \& Li, 2018; Liao, 2018).

Therefore, our analysis reveals that a sustainable image is an essential factor to enhance performance through environmental and social strategies, showing that sustainability initiatives are valued when such efforts are promoted. Many organizations have realized that integrating sustainability in their management system is essential, as they cannot succeed without it in a global world, or engage in hyper-competitive relationships. Accordingly, this process leads to an increase in sales, reduces costs, strengthens relationships with stakeholders and, consequently, increases profits.

\subsection{Stakeholder perceptions}

A third performance outcome linked to the integration of sustainability in the corporate strategy suggested by 62 managers is stakeholder perceptions. They pointed out that a large proportion of the stakeholders, from clients to potential investors, from employees to financial institutions, report that sustainability issues are a relevant factor in their decision-making process. For example, customers are more conscious than in the past of the sustainability of products and services, and the responsibility of organizations, thus seeking information on production methods and the environmental impact of the firm's activities. Therefore, non-economic benefits, such as improving brand reputation, customer retention, creating value for the entire community, and safeguarding the environment must be taken into account. Our respondents asserted that this process translates into several advantages for a sustainabilityoriented company. For example, deferring payments, forecasting future orders and providing general information on the future strategy are enabled when customers perceive an organization as more sustainable than its competitors. In the same way, the relationship with financial institutions allows easier access to credit lines and supporting cash flow needs. In addition, potential investors may perceive reduced risk when investing in firms with lower borrowing and capital costs. Therefore, in adopting sustainable practices, stakeholders derive greater satisfaction and perceive the organization as better than others that do not implement sustainable practices. The positive relationship between a sustainable corporate strategy and stakeholder perceptions brings advantages to business performance in terms of satisfying stakeholder needs and developing trusting relationships with them. With respect to the first outcome (image and reputation), this is more externally oriented and focused on the needs and perceptions of all stakeholders. 
The data suggest that one of the most important ways that sustainable integration can enhance a company's performance is through the firm's positioning with stakeholders.

\subsection{Cultural change}

The last performance outcome that emerged is the cultural change generated in an organization when a sustainable strategy is implemented. Forty-three managers highlighted that the integration process is supported by a sustainability culture in both the company and individuals. This dual role of the cultural dimension is particularly interesting and, as numerous respondents suggested, is a driver of implementing sustainability in the corporate strategy. As a performance outcome, it impacts the organizational culture and reinforces and supports the corporate strategy in redefining and developing sustainability goals. The respondents asserted that strategically integrating sustainability in the organization's culture can be achieved by implementing strategic goals including co-working spaces, employee involvement, and university and public institution collaborations. For example, the propensity to increase and involve human capital in defining a sustainability plan where employees feel safe to express themselves and share information and ideas will bring benefits to the company and the people involved, optimizing production and integrating different resources. This finding is in line with SDG8 (2030 Agenda) of the sustainable development goals (SDGs) to "promote sustained, inclusive, and sustainable economic growth, full and productive employment and decent work for all", albeit scarcely addressed and discussed in the literature. Moreover, growth and cultural change require a solid and concrete network of relationships that can lead to different opportunities. In this context, conveying and increasing the propensity for a sustainability culture facilitates achieving the SDGs. Accordingly, this requires focusing on strategies based on reward systems, strengthening external collaborations and defining cultural initiatives with schools and universities.

\section{Sustainable management practices and main challenges}

As previously mentioned, after presenting the advantages for organizations that implement sustainability-oriented corporate strategies, we analysed the managerial practices and measures actually used to integrate sustainability at the strategic level, as well as the main challenges of the integration process.

To this end, after the initial interviews, we analysed the managers' responses, identifying the strategic goals and KPIs emerging from managerial practice, including the main challenges and critical issues of integrating sustainability in the corporate strategy. After our analysis, we once more contacted the respondents (second round), summarized our interpretation of the results and provided them with the KPI system generated (Table 2), the future challenges and the 
Table 2 Sustainability KPIs

\begin{tabular}{|c|c|c|}
\hline Environmental goals & Sustainability performance measures & Frequency $(\%)$ \\
\hline Reduce utility consumption & $\begin{array}{l}\text { Energy intensity } \\
\text { Electricity consumption } \\
\text { Gas consumption } \\
\text { Soil use } \\
\text { Water use }\end{array}$ & 75 \\
\hline Reduce emissions (air, water and soil) & $\begin{array}{l}\text { Emission of ozone-depleting substance } \\
\text { Emission of greenhouse gases } \\
\text { Emission of other environmentally affecting } \\
\text { gases } \\
\text { Carbon footprint (Carbon footprint) } \\
\text { Sulphur dioxides (SOx emissions) } \\
\text { Nitrogen oxides (NOx emissions) }\end{array}$ & 65 \\
\hline Reduce radiation, noise and vibrations & $\begin{array}{l}\text { Environmental accidents } \\
\text { Level of noise } \\
\text { Level of vibrations }\end{array}$ & 60 \\
\hline $\begin{array}{l}\text { Waste: efforts to address } \\
\text { "green-ness" }\end{array}$ & $\begin{array}{l}\text { Waste reduction rate } \\
\text { Percentage of waste generated per thousand } \\
\text { product units } \\
\text { Dangerous waste generated rate } \\
\text { Percentage of hazardous material over total } \\
\text { waste } \\
\text { Percentage of reusable/recycled material } \\
\text { Pollution indicators (emissions to air, effluent, } \\
\text { solid waste) } \\
\text { Waste generated from products and materials }\end{array}$ & 50 \\
\hline Use renewable sources & $\begin{array}{l}\text { Renewable energy percentage } \\
\text { Percentage of reusable/recycled material } \\
\text { Renewable electric sources } \\
\text { Sustainable water use }\end{array}$ & 50 \\
\hline Social goals & Sustainability performance measures & Frequency $(\%)$ \\
\hline $\begin{array}{l}\text { Employees' acceptance of organiza- } \\
\text { tional change }\end{array}$ & $\begin{array}{l}\text { Employee satisfaction rate } \\
\text { Employee turnover rate } \\
\text { Number of training hours per employee } \\
\text { Rate of employees that are shareholders }\end{array}$ & 80 \\
\hline Environment and work conditions & $\begin{array}{l}\text { Employment rate } \\
\text { Internal relation rate } \\
\text { Health and safety rate } \\
\text { Training rate } \\
\text { Diversity rate } \\
\text { Opportunity rate }\end{array}$ & 60 \\
\hline Human rights & $\begin{array}{l}\text { Equality (male to female ratio) } \\
\text { Child labour } \\
\text { Forced labour } \\
\text { Disciplinary actions } \\
\text { Social security }\end{array}$ & 65 \\
\hline Society & $\begin{array}{l}\text { Charity donations (community rate) } \\
\text { Social initiatives at national and local levels } \\
\text { Expenses for social initiatives } \\
\text { Percent participants in social initiatives } \\
\text { Corruption }\end{array}$ & 55 \\
\hline
\end{tabular}


Table 2 (continued)

\begin{tabular}{|c|c|c|}
\hline Social goals & Sustainability performance measures & Frequency $(\%)$ \\
\hline Responsibility & $\begin{array}{l}\text { Consumer safety } \\
\text { Privacy }\end{array}$ & 40 \\
\hline Economic goals & Sustainability performance measures & Measures \\
\hline Increasing return on investment & $\begin{array}{l}\text { Cost of ownership linked to energy, cost } \\
\text { consumption, cost of social and environmen- } \\
\text { tal tax } \\
\text { Growth of gross margin } \\
\text { Total costs and investments relating to envi- } \\
\text { ronmental protection }\end{array}$ & 90 \\
\hline Increase revenues & $\begin{array}{l}\text { Additional revenue through: additional price } \\
\text { premium brand differentiation, sustainable } \\
\text { innovations }\end{array}$ & 80 \\
\hline Enhance product technology & $\begin{array}{l}\text { Total investments in technology } \\
\text { New environmentally sound processes intro- } \\
\text { duced } \\
\text { New environmentally sound product develop- } \\
\text { ment } \\
\text { Response to environmental product requests } \\
\text { Amount of environmentally safe alternatives }\end{array}$ & 80 \\
\hline Guarantee quality & $\begin{array}{l}\text { Production sites with environmental certifica- } \\
\text { tion } \\
\text { Mutual planning for environmental improve- } \\
\text { ments } \\
\text { Environmental information accuracy } \\
\text { Supplier rejection rate }\end{array}$ & 50 \\
\hline
\end{tabular}

critical issues that we perceived. In the following subsections, we discuss the output in line with the discussion with our respondents with regard to first the practices and measures, and then the challenges and critical issues.

\subsection{Practices and measures}

Addressing the integration process, the managers discussed the various ways in which their companies have invested in implementing sustainable practices. The findings suggest that the main initiatives adopted are improving energy efficiency (e.g. purchasing new energy-efficient machinery and/or installing photovoltaic systems). These initiatives aim to reduce the use of natural resources (by using materials with a high recyclability rate), decarbonizing the economy, supporting their local communities and investing in employee training, thus increasing engagement with people and creating added value, not only for the firm but also for the community. The managers discussed the relevant role of sustainability KPIs aimed at implementing, monitoring and measuring the sustainability strategy adopted. In fact, the managers unanimously agreed on one point: a KPI system is a necessary tool, a bridge between sustainability and the corporate strategy, to understand exactly where the company is heading and to check its trajectory is in line with the agenda. Managers 
must be able to quickly correct and adapt to changing market conditions. If they want to succeed in an extremely competitive market, they need a way to measure progress in real time, adapting their actions on the basis of the KPIs. Also emerging from the interviews was that the managers use several sustainable KPIs in practice to implement the sustainability strategy. We asked the respondents to indicate the sustainability dimension mostly considered and the three sustainable goals associated with the dimension. We then calculated the reported percentages based on the frequency of the goals. We then discussed each goal to identify the measures most used in practice, reporting all the indicators associated with the specific goal identified. For the environmental dimension, the goal most considered in managerial practice is the reduction of utility consumption ( $75 \%$ of managers), for the social dimension, employees' acceptance of organizational change (80\%) and, finally, for the economic dimension, increasing the return on investments $(90 \%)$. In addition, we identified the KPIs most used for each strategic goal. Table 2 details the KPIs adopted for each specific dimensions.

The strategic goals and sustainable KPIs presented in Table 2 are considered a useful tool to implement sustainability at the strategic level, and a starting point for practical applications in future studies. As specifically discussed with the respondents, all aim to enable implementation, monitoring and management of sustainability issues, thus facilitating the integration process in managerial practice.

\subsection{Challenges and critical issues}

The main incentive for organizations to adopt sustainable strategies and policies is the possibility of gaining a competitive advantage. In fact, changing towards sustainability may prompt a real evolution of the competitive scenario, provided that organizations are proactive and ready to make internal changes, adapting their structures in a short time-scale to remain competitive. Organizations that adapt sooner and do not consider sustainability as a difficult challenge with few justifications are better able to gain a leadership position than competitors.

According to the managers interviewed, the benefits linked to implementing sustainability exceed the costs. However, one issue that emerged concerns the quantification of the costs and benefits. This is a significant criticism that impacts the decision to implement sustainable strategy. All respondents mentioned that a large part of the decision is driven by economic expectations in terms of cost reduction and revenue growth, as confirmed by the literature (Bhattacharya \& Sen, 2004; Epstein $\&$ Wisner, 2001). Specific qualitative and quantitative measures are thus needed to evaluate the performance of the sustainability strategy adopted, a challenge that future studies and managerial practice might address.

In addition, $75 \%$ of respondents recalled another important issue: many companies are still convinced that sustainability is a cost, impedes their growth and leads to unstable innovation, without yet realizing that sustainable strategies bring many positive effects. Many firms feel sustainability is a legal constraint, where the environmental repercussions and financial results contradict the facts. Consequently, 


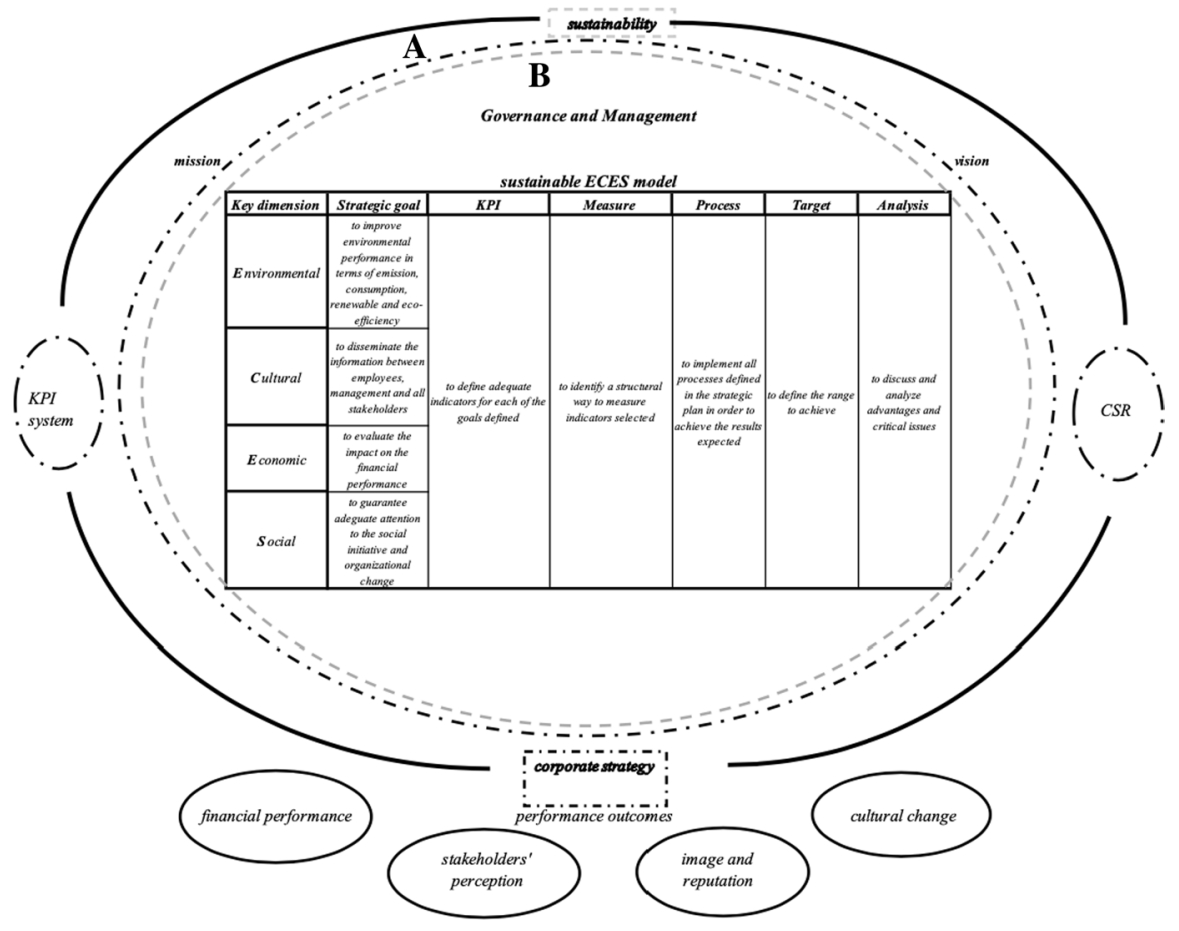

Fig. 3 ECES performance model

integration is not advancing quickly enough, mainly because of the cultural barrier in organizations and the lack of trust in the financial benefits that derive from a sustainable strategy. Indeed, managers are still too focused on short-term financial results, a critical issue that hinders the integration process, calling for a cultural change to achieve an integrated view of the corporate system.

\section{Sustainable governance and future research directions}

In line with our findings, we provide a theoretical framework (Fig. 3), as an extension of Fig. 1, that we call the ECES (environmental/cultural/economic/social) model. Based on the respondents' needs and expectations, in this last (third) round of interviews, we presented our model to the managers and discussed its potential for corporate performance. We incorporated the modifications that the respondents suggested to improve the model's effectiveness.

Through a careful analysis of the literature and the managers' experiences, we provide a clear picture of the role of the key value drivers of sustainable development. The framework is based on three main pillars: (1) the way to integrate sustainability in the corporate strategy; (2) the practices and measures to support integration; and (3) the advantages firms may obtain thanks to implementing a sustainable corporate strategy. 
With regard to the first pillar, the model suggests incorporating the sustainability level (B) in the corporate strategy (A) during the planning and formulation stage to enable integration of all the sustainability dimensions in the firm's corporate management and governance. The strategic alignment of CSR and the KPI system allows linking of sustainability and the corporate strategy, in turn leading to effective integration of the sustainability strategy in the early strategy formulation stage.

With regard to the second pillar, the model identifies the key sustainability dimensions to include in the corporate strategy and, alongside the traditional TBL, the fourth cultural dimension, aimed at developing a sustainability-oriented mindset and, thus, effective integration. For each dimension, a sustainability plan needs to be prepared based on a multidimensional scorecard of the strategic goals, KPIs, measures, processes, targets and analyses. This approach is essential to design a structured system that allows managers to implement sustainable strategies based on the fundamental drivers of sustainability development. We highlight the cultural dimension (organizational culture) separately from the social dimension because of its strategic role in supporting the integration process. Indeed, $60 \%$ of our respondents highlighted the need to consider this additional dimension as fundamental to developing and implementing a sustainable strategy. For example, one of the managers stated, "The cultural context is the key to build a favourable climate that allows achieving sustainable integration. The cultural factors explain, at the same time, the fears and perspectives deeply embedded in the organization's mindset".

Finally, the model clearly highlights the potential advantages of integrating sustainability in the corporate strategy to support decision-making when adopting a sustainability strategy.

In view of our findings, the ECES conceptual framework is conceived as a way to support the integration process, aiming to provide a clear view of the how (strategic alignment incorporating sustainability in strategic planning), the what (practices and measures) and the why (performance outcomes) of implementing a corporate sustainability strategy. This framework can be considered an additional first step to achieving sustainable integration, albeit requiring further studies and implementation.

\section{Conclusion and discussion}

Integrating sustainability in the corporate strategy is a relevant topic in the literature and in managerial practice. Managers must drive the company responsibly and create an appropriate supervisory structure that supports the firm's value creation process to meets human needs without destroying resources.

The results of our study can be summarized as follows. Integrating sustainability in the corporate strategy positively impacts financial performance, image and reputation, despite some studies suggesting a negative relationship. The literature has thus far mainly focused on the environmental, social and economic dimensions of 
sustainability, neglecting the relevant cultural dimension. Overall, our findings point to the need for an integrated approach to achieve sustainable development.

\subsection{Contributions of the study}

In this study, we address two specific research questions aimed at improving current knowledge of the advantages, sustainability value drivers, measures and challenges of integrating sustainability in the corporate strategy.

Our first research question sought to identify the advantages of integrating sustainability initiatives in strategic decision-making, providing new empirical evidence of the perceived advantages of adopting a corporate sustainability strategy. Accordingly, we identify and discuss four main performance outcomes: financial performance, image and reputation, stakeholder perceptions and cultural change. Our study confirms and reinforces prior literature suggesting the advantages of sustainability initiatives in terms of financial performance, image and reputation. However, the two additional performance outcomes we examine (stakeholder perceptions and cultural change) have received less scholarly attention, yet each of these dimensions needs to be carefully analysed through the governance lens when implementing sustainability at the strategic level.

Our second research question sought to determine how sustainability can be integrated into the corporate strategy with a view to sustainable development. We constructed a sustainable KPI system as a tool to support the integration process in view of long-term advantages. Our findings potentially show managers how to achieve sustainable integration, respecting the wellbeing of our planet while also benefitting the organization. We used our findings to develop the ECES model that encapsulates all the sustainability dimensions, translating the firm's strategic objectives into a set of measures leading to sustainable value creation.

We believe the paper contributes to the existing literature in several ways. First, we provide a clear overview of the advantages, practices and measures, challenges and critical issues in adopting sustainable strategies, and managers' perceptions of sustainable value drivers linked to corporate performance. Second, we extend the current literature by advancing the cultural dimension that has thus far remained overlooked from a strategic and accounting perspective. Third, by integrating sustainability, our conceptual framework can help managers implement and monitor their corporate sustainability strategy.

\subsection{Theoretical and practical implications}

Our study is relevant to academics and practitioners alike. Researchers might use our findings to test the efficiency of the sustainability framework through analysing the impact on corporate performance in a specific time period (for example, 2 or more years) as well as the sustainable corporate strategy approach implemented to achieve superior performance. Practitioners dealing with sustainability issues at the 
strategic level can use the proposed framework as a strategic management tool to support the decision-making process.

The advantages of adopting an integrated sustainability-oriented approach as perceived by managers provide a clear view of the potential effects of implementing a sustainable corporate strategy on performance. Through emphasizing the relevance of sustainability issues, the KPI system indirectly drives the integration of sustainability in the corporate strategy, informing the organizational culture, supporting the planning and implementation of sustainable strategies, and measuring strategic performance. In addition, the proposed KPI system is an important step in guiding and supporting future studies and managerial practice to integrate the environmental, cultural, economic and social dimensions in corporate governance.

However, more effort is needed to identify the relationship between sustainable KPIs and performance, particularly which KPIs are positively linked to performance. Our proposed scorecard is a starting point that needs further investigation to determine the effectiveness of the indicators on overall firm performance, as well as on selecting, using and monitoring sustainability indicators.

Moreover, our study suggests that a cultural change in organizations is required to promote understanding of the fundamental importance of sustainability.

Finally, the theoretical framework enables the key value drivers of sustainable development to be pinpointed from an integrated perspective, a strategic tool to support the decision-making process with relevant implications for practice. Our theoretical development paves the way for future studies to explore the issues around integrating sustainability in the corporate strategy.

\subsection{Limitation of the study}

As with any research, this study has some limitations. Specifically, we have focused on the contributions of respondents more open to/positive toward sustainability, potentially leading to subjective bias. Given that the interviewer interprets and contextualizes qualitative data, objectivity cannot be assured, and therefore a practical implementation of the theoretical model is required. In addition, the cultural dimension requires further investigation; for example, future studies might explore the key drivers related to this dimension in organizations.

To overcome these limitations, future research could use the proposed model as a starting point to develop an integrated approach through a pilot study. Practical cases implementing the model, including the sustainability KPIs, are needed to improve our findings and achieve a better understanding of the potential of a sustainable performance management system. 
Table 3 Questionnaire

Section 1 - Competitive advantages

1. Can you explain how the use of a sustainable strategy impacts the value creation process?

2. What are the main advantages in integrating sustainability in the strategy? Can you explain why?

3. How do you measure these advantages and their impact?

4. What do you think about the role of sustainability in management and governance?

5. Are managers interested in sustainability issues?

Section 2 - Practices and measures

6. Based on experience, can you explain which sustainability dimension is mostly considered in practice?

7. Can you explain why?

8. For each dimension, can you provide a set of three strategic goals used in practice?

9. In addition, can you identify the KPIs mostly used for each of the strategic goals provided?

10. Can you talk about the sustainable development goals (SDGs) and how they are considered in practice in view of the Agenda 2030?

11. What are the actions and tools used to integrate SDGs in the strategy?

12. What are the main certifications used and their impact on the strategy?

Section 3 - Integration, challenges and critical issues

13. Do you think it is possible to add value by integrating sustainability in the corporate strategy?

14. Has your company invested in implementing sustainable practices? Why? (whether yes or no) How?

15. Which is the main investment field?

16. Can you explain the main aspects that managers focus on when they evaluate the investment?

17. How do you integrate sustainability, and in general CSR issues, in the corporate strategy?

18. Can you talk about the critical issues linked to this integration?

19. What do you think about the integration achieved in your company?

20. What are the main challenges linked to the integration?

\section{Appendix}

See Appendix Table 3.

Funding Open access funding provided by Università degli Studi di Roma Tor Vergata within the CRUICARE Agreement.

Open Access This article is licensed under a Creative Commons Attribution 4.0 International License, which permits use, sharing, adaptation, distribution and reproduction in any medium or format, as long as you give appropriate credit to the original author(s) and the source, provide a link to the Creative Commons licence, and indicate if changes were made. The images or other third party material in this article are included in the article's Creative Commons licence, unless indicated otherwise in a credit line to the material. If material is not included in the article's Creative Commons licence and your intended use is not permitted by statutory regulation or exceeds the permitted use, you will need to obtain permission directly from the copyright holder. To view a copy of this licence, visit http://creativecommons.org/licen ses/by/4.0/. 


\section{References}

Acquaye, A., Genovese, A., Barrett, J., \& Koh, S. C. L. (2014). Benchmarking carbon emissions performance in supply chains. Supply Chain Management, 19, 306-321. https://doi.org/10.1108/ SCM-11-2013-0419

Adams, C. A. (2002). Internal organisational factors influencing corporate social and ethical reporting: beyond current theorizing. Accounting, Auditing and Accountability Journal, 15(2), 223-250. https://doi.org/10.1108/09513570210418905

Adams, C. A., \& Frost, G. R. (2008). Integrating sustainability reporting into management practices. Accounting Forum, 32, 288-302. https://doi.org/10.1016/j.accfor.2008.05.002

Azevedo, S. G., Carvalho, H., Duarte, S., \& Cruz-Machado, V. (2012). Influence of green and lean upstream supply chain management practices on business sustainability. IEEE Transactions on Engineering Management, 59, 753-765. https://doi.org/10.1109/TEM.2012.2189108

Bai, C., \& Sarkis, J. (2014). Determining and applying sustainable supplier key performance indicators. Supply Chain Management, 19, 275-291. https://doi.org/10.1108/SCM-12-2013-0441

Bansal, P., \& Bogner, W. (2002). Deciding on ISO 14001: economics, institutions, and context. Long Range Planning, 35(3), 269-290. https://doi.org/10.1016/S0024-6301(02)00046-8

Barnett, M. L. (2007). Stakeholder influence capacity and the variability of financial returns to corporate social responsibility. Academy of Management Review, 32(3), 794-816. https://doi.org/10. 5465/amr.2007.25275520

Barnett, M. L., \& Salomon, R. M. (2006). Beyond dichotomy: the curvilinear relationship between social responsibility and financial performance. Strategic Management Journal, 27(11), 1101-1122.

Bhattacharya, C. B., \& Sen, S. (2004). Doing better at doing good: when, why, and how consumers respond to corporate social initiatives. California Management Review, 47(1), 9-24. https://doi. org/10.2307/41166284

Bhattacharyya, A. (2019). Corporate environmental performance evaluation: a cross-country appraisal. Journal of Cleaner Production. https://doi.org/10.1016/j.jclepro.2019.117607

Bini, L., Dainelli, F., \& Giunta, F. (2015). Is a loosely specified regulatory intervention effective in disciplining management commentary? The case of performance indicator disclosure. Journal of Management \& Governance, 21(1), 63-91. https://doi.org/10.1007/s10997-015-9334-0

Bisbe, J., \& Malagueño, R. (2012). Using strategic performance measurement systems for strategy formulation: does it work in dynamic environments? Management Accounting Research, 23, 296-311. https://doi.org/10.1016/j.mar.2012.05.002

Bortolotti, T., Boscari, S., \& Danese, P. (2015). Successful lean implementation: organizational culture and soft lean practices. International Journal of Production Economics, 160, 182-201. https://doi. org/10.1016/j.ijpe.2014.10.013

Braune, E., Charosky, P., \& Hikkerova, L. (2019). Corporate social responsibility, financial performance and risk in times of economic instability. Journal of Management \& Governance, 23(4), 1007-1021. https://doi.org/10.1007/s10997-019-09476-y

Burke, L., \& Logsdon, J. M. (1996). How corporate social responsibility pays off. Long Range Planning, 29(4), 495-502. https://doi.org/10.1016/0024-6301(96)00041-6

Burney, L., Henle, C., \& Widener, S. (2009). A path model examining the relations among strategic performance measurement system characteristics, organizational justice, and extra- and in-role performance. Accounting, Organizations and Society, 34(3-4), 305-341. https://doi.org/10.1016/j.aos. 2008.11.002

Busco, C., Quattrone, P., \& Riccaboni, A. (2007). Management accounting. Issues in interpreting its nature and change. Management Accounting Research, 18(2), 125-149. https://doi.org/10.1016/j. mar.2007.04.003

Cai, W., \& Li, G. (2018). The drivers of eco-innovation and its impact on performance: evidence from China. Journal of Cleaner Production, 176, 110-118. https://doi.org/10.1016/j.jclepro.2017.12.109

Cantele, S., \& Zardini, A. (2018). Is sustainability a competitive advantage for small businesses? An empirical analysis of possible mediators in the sustainability-financial performance relationship. Journal of Cleaner Production, 182, 166-176. https://doi.org/10.1016/j.jclepro.2018.02.016

Chalmeta, R., \& Palomero, S. (2011). Methodological proposal for business sustainability management by means of the balanced scorecard. Journal of the Operational Research Society, 62(7), 13441356. https://doi.org/10.1057/jors.2010.69 
Charlo, M. J., Moya, I., \& Muñoz, A. M. (2013). Sustainable development and corporate financial performance: a study based on the FTSE4Good IBEX index. Business Strategy \& Environment, 24(4), 277-288. https://doi.org/10.1002/bse.1824

Chenhall, R. H. (2005). Integrative strategic performance measurement systems, strategic alignment of manufacturing, learning and strategic outcomes: an exploratory study. Accounting, Organizations and Society, 30(5), 395-422. https://doi.org/10.1016/j.aos.2004.08.001

Cinquini, L., \& Mitchell, F. (2005). Success in management accounting: lessons from the activity-based costing/management experience. Journal of Accounting \& Organizational Change, 1, 63-78. https://doi.org/10.1108/18325910510635290

Cinquini, L., \& Tenucci, A. (2010). Strategic management accounting and business strategy: a loose coupling? Journal of Accounting \& Organizational Change, 6(2), 228-259. https://doi.org/10.1108/ 183259110110487

De Villiers, C., Rouse, P., \& Kerr, J. (2016). A new conceptual model of influences driving sustainability based on case evidence of the integration of corporate sustainability management control and reporting. Journal of Cleaner Production, 136, 78-85. https://doi.org/10.1016/j.jclepro.2016.01.107

Eisenhardt, K. M., \& Graebner, M. E. (2007). Theory building from cases: opportunities and challenges. Academy of Management Journal, 50(1), 25-32. https://doi.org/10.5465/amj.2007.24160888

Epstein, M. J., \& Wisner, P. S. (2001). Using a balanced scorecard to implement sustainability. Environmental Quality Management, 11(2), 1-10. https://doi.org/10.1002/tqem.1300

Farias, L. M. S., Santos, L. C., Gohr, C. F., Oliveira, L. C., \& Amorim, M. H. (2019). Criteria and practices for lean and green performance assessment: systematic review and conceptual framework. Journal of Cleaner Production, 218, 746-762. https://doi.org/10.1016/j.jclepro.2019.02.042

Figge, F., Hahn, T., Schaltegger, S., \& Wagner, M. (2002). The sustainability balanced scorecard: linking sustainability management to business strategy. Business Strategy \& Environment, 284, 269-284. https://doi.org/10.1002/bse.339

Geng, R., Mansouri, S. A., \& Aktas, E. (2017). The relationship between green supply chain management and performance: a meta-analysis of empirical evidences in Asian emerging economies. International Journal of Production Economics, 183, 245-258. https://doi.org/10.1016/j.ijpe.2016.10.008

Hristov, I., \& Chirico, A. (2019). The role of sustainability key performance indicators (KPIs) in implementing sustainable strategies. Sustainability, 11(20), 5742. https://doi.org/10.3390/su11205742

Hsu, F. J., \& Chen, Y. (2015). Is a firm's financial risk associated with corporate social responsibility? Management Decision, 53, 2175-2199. https://doi.org/10.1108/MD-02-2015-0047

Hull, C. E., \& Rothenberg, S. (2008). Firm performance: the interactions of corporate social performance with innovation and industry differentiation. Strategic Management Journal, 29(7), 781-789. https://doi.org/10.1002/smj.675

Langfield-Smith, K. (2007). A review of quantitative research in management control systems and strategy. In C. S. Chapman, A. G. Hopwood, \& M. D. Shields (Eds.), Handbook of management accounting research. (Vol. 2, pp. 753-784). Elsevier.

Lawrence, P. R., \& Lorsch, J. W. (1967). Differentiation and integration in complex organizations. Administrative Science Quarterly, 12(1), 1-47. https://doi.org/10.2307/2391211

Le Tellier, M., Berrah, L., Stutz, B., Audy, J. F., \& Barnabé, S. (2019). Towards sustainable business parks: a literature review and a systemic model. Journal of Cleaner Production, 216, 129-138. https://doi.org/10.1016/j.jclepro.2019.01.145

Lewandowski, S. (2017). Corporate carbon and financial performance: the role of emission reductions. Business Strategy \& Environment, 1211, 1196-1211. https://doi.org/10.1002/bse.1978

Liao, Z. (2018). Environmental policy instruments, environmental innovation and the reputation of enterprises. Journal of Cleaner Production, 171, 1111-1117. https://doi.org/10.1016/j.jclepro.2017.10. 126

Lisi, I. E. (2015). Translating environmental motivations into performance: the role of environmental performance measurement systems. Management Accounting Research, 29, 27-44. https://doi.org/ 10.1016/j.mar.2015.06.001

Magon, R. B., Thomé, A. M. T., Ferrer, A. L. C., \& Scavarda, L. F. (2018). Sustainability and performance in operations management research. Journal of Cleaner Production, 190, 104-117. https:// doi.org/10.1016/j.jclepro.2018.04.140

McWilliams, A., \& Siegel, D. (2000). Corporate social responsibility and financial performance: correlation or misspecification? Strategic Management Journal, 21(5), 603-609. https://doi.org/10.1002/ (SICI)1097-0266(200005)21:5\%3c603::AID-SMJ101\%3e3.0.CO;2-3 
McWilliams, A., \& Siegel, D. (2001). Corporate social responsibility: a theory of the firm perspective. Academy of Management Review, 26(1), 117-127. https://doi.org/10.5465/amr.2001.4011987

Michelon, G., \& Parbonetti, A. (2010). The effect of corporate governance on sustainability disclosure. Journal of Management \& Governance, 16(3), 477-509. https://doi.org/10.1007/s10997-010-9160-3

Miroshnychenko, I., Barontini, R., \& Testa, F. (2017). Green practices and financial performance: a global outlook. Journal of Cleaner Production, 147, 340-351. https://doi.org/10.1016/j.jclepro. 2017.01.058

Morioka, S. N., \& de Carvalho, M. M. (2016). A systematic literature review towards a conceptual framework for integrating sustainability performance into business. Journal of Cleaner Production, 136, 134-146. https://doi.org/10.1016/j.jclepro.2016.01.104

Morrow, D., \& Rondinelli, D. (2002). Adopting corporate environmental management systems: motivations and results of ISO 14001 and EMAS certification. European Management Journal, 20(2), 159-171. https://doi.org/10.1016/S0263-2373(02)00026-9

Parisi, C. (2012). The impact of organisational alignment on the effectiveness of firms' sustainability strategic performance measurement systems: an empirical analysis. Journal of Management \& Governance, 17(1), 71-97. https://doi.org/10.1007/s10997-012-9219-4

Perego, P., \& Hartmann, F. (2009). Aligning performance measurement systems with strategy: the case of environmental strategy. Abacus, 45, 397-428. https://doi.org/10.1111/j.1467-6281.2009.00297.x

Przychodzen, J., \& Przychodzen, W. (2015). Relationships between eco-innovation and financial performance: evidence from publicly traded companies in Poland and Hungary. Journal of Cleaner Production, 90, 253-263. https://doi.org/10.1016/j.jclepro.2014.11.034

Sahut, J.-M., Peris-Ortiz, M., \& Teulon, F. (2019). Corporate social responsibility and governance. Journal of Management and Governance, 23(4), 901-912. https://doi.org/10.1007/s10997-019-09472-2

Suganthi, L. (2019). Examining the relationship between corporate social responsibility, performance, employees' pro-environmental behavior at work with green practices as mediator. Journal of Cleaner Production, 232, 739-750. https://doi.org/10.1016/j.jclepro.2019.05.295

Trianni, A., Cagno, E., Neri, A., \& Howard, M. (2019). Measuring industrial sustainability performance: empirical evidence from Italian and German manufacturing small and medium enterprises. Journal of Cleaner Production, 229, 1355-1376. https://doi.org/10.1016/j.jclepro.2019.05.076

Wang, Q., Dou, J., \& Jia, S. (2016). A meta-analytic review of corporate social responsibility and corporate financial performance: the moderating effect of contextual factors. Business \& Society, 55(8), 1083-1121. https://doi.org/10.1177/0007650315584317

Xie, J., Nozawa, W., Yagi, M., Fujii, H., \& Managi, S. (2019). Do environmental, social, and governance activities improve corporate financial performance? Business Strategy \& Environment, 28, 286-300. https://doi.org/10.1002/bse.2224

Xie, X., Huo, J., \& Zou, H. (2019). Green process innovation, green product innovation, and corporate financial performance: a content analysis method. Journal of Business Research, 101, 697-706. https://doi.org/10.1016/j.jbusres.2019.01.010

Zhu, Q., Sarkis, J., \& Lai, K. H. (2012). Examining the effects of green supply chain management practices and their mediations on performance improvements. International Journal of Production Research, 50, 1377-1394. https://doi.org/10.1080/00207543.2011.571937

Publisher's Note Springer Nature remains neutral with regard to jurisdictional claims in published maps and institutional affiliations.

Ivo Hristov is a Ph.D in Management. He is contract lecturer of Performance Management at the University of Rome Tor Vergata, Department of Management and Law where he is also an Assistant Professor of Managerial Accounting. He also teaches Financial Reporting at the University of Tuscia. His research areas include Corporate Governance, Accounting, Performance Management and sustainable strategies.

Antonio Chirico is a PhD in Banking and Finance. He is Associate Professor of Accounting at the Department of Management and Law, University of Rome "Tor Vergata" where he teaches Financial Reporting and Managerial Control. His main research interests concern the issues of financial statements, performance analysis, planning and management control in both private and public sectors. 
Francesco Ranalli is Full Professor of Accounting at the Department of Management and Law, University of Rome "Tor Vergata" where he teaches courses of Financial Reporting and Financial Analysis. His research activity covers mainly the areas of accounting, financial statements, governance and performance analysis issues in both private and public sectors. 